\title{
Personal development in the virtuality; online activities for individual and group growth
}

Saiz-Sánchez, Héctor ${ }^{a}$; Martínez-DeLaTorre, Javier ${ }^{\mathrm{a}}$; Esteller-Curto, Roger ${ }^{\mathrm{a}}$; Serradell-López, Enric ${ }^{\text {}}$; Gallego-Navarro, Teresa ${ }^{c}$ and Rubert-Albiol, Andrea ${ }^{a}$

${ }^{\mathrm{a}}$ Centre for the Innovation and Development of Education and Technology, Spain, ${ }^{\mathrm{b}}$ Universitat Oberta de Catalunya, Spain, ${ }^{\mathrm{c}}$ Universitat Jaume I, Spain

\begin{abstract}
Online teaching is commonly offered for courses and it is aimed students acquire specific skills based on the subject requirements. Regarding soft-skills, collaborative and creative activities are usually deployed face-to-face in contrast to online environments, where communication, group dynamics and activities that require interactivity among the participants can be managed easier. Because of this we loose skills acquisition opportunities and other potential benefits of real collaboration mediated by on-line environments.

We propose an ICT-based method appropriated for project-based learning, innovative teams and personal development. It has 7 phases and has been designed under the theories of field theories of humanism with the main aim to make possible that everybody in the on-line platform can grow and develop individually together with the group. Professor can apply this as a whole (the 7 phases) or some of them as we have related the phases with on-line tasks. We tested this method with a group of 17 post-graduate students. We concluded that when members have enough maturity and experience, these ICT-based-methods make shared learning possible, with great impact on the course skills and competences, but also on soft skills, which are acquired informally while learning the main course subject.
\end{abstract}

Keywords: shared learning; project-based learning; Ed-Way; Edueca; eLearning; collaboration. 


\section{Background}

eLearning (Clark and Mayer, 2016) has favored the development of technological tools and new educational paradigms with an ongoing development (Eurostat, 2017). Virtual teaching is not only content delivery, that is the traditional Virtual Learning Environment (VLE) (Weller, 2007), or management; Learning Management System (LMS) (Watson, 2007), but also creating comfortable learning places; Personal Learning Environments (PLE) (Veletsianos, 2010), connections with people; Personal Learning Network (PLN) (Couros, 2010), still with challenges (Cabero-Almenara, 2016) pending to solve.

In this paper we prefer to focus on the benefits on networking (PLN) and the growth of individuals by building their own place (PLE). We tested these methods for shared learning, where we are part of a group and at the same time we aim the growth as individuals.

We have focused the design of the method we propose on two different cases. The first one is centred on the Universitat Jaume I, Department of Mechanics and Engineering, by Teresa Gallego and Belinda López-Mesa (2007) where they employ a project-based learning (PBL) approach; students work on real project which are used for practical activities. Students are being trained on the specific competences while having to know each other and complicating the definition of group members (Gallego \& López-Mesa, 2007, p.5). PBL methodology provides benefits while challenges.

The second study-case considered for our methodology proposal is based on the Universitat Oberta de Catalunya, School of Business and Economics (Serradell-López 2014, FitóBertran, et Al. 2014), where a student group manages different virtual business and different skills are exploited: communication, group participation, getting global perspective, requiring the specialization of the individuals while, at the same time, acquiring group strategy.

Based on the previous study cases needs, we proposed and tested a 7-phase group development process which takes into consideration the individual facets and aims with global and group strategy. The implementation of an educational methodology centered on personal development and personal reflection needs to respect working criteria based on the own perceptions of the groups and each one of its components. Therefore, we need to respect the following premises under the context of humanist field theories:

1. Every group of people tends to find their own inner balance. People who takes part in a group, tend to self-organize and do it from a chaotic perspective (Friedman, 2002).

2. Every human group goes through different phases while its members interact. All of them must be attended in order to respect the perceptions, feelings and learning 
needs of each group (Lewin, 1947); orientation phase, phase of conflict, grouping phase, team phase.

3. Every group requires a systemic approach that allows a multifunctional and multidimensional analysis of the existing processes in learning group (Satir, 1988).

4. Every group requires interaction in its right measure. The protagonism of the group is within the group itself and everything that happens in that context (Polster, 1974).

5. Every group has to be stimulated to find their own reality. All facilitation behavior within the group must be focused to their own self-organization and the elaboration of their own reflections and responses (Goodman, 1966).

6. Every group needs a functional and bio-positive approach. To do this, we must emphasize the internal processes of reflection within a group (Goodman, et Al. 1951).

7. Every group needs a work structure that supports its own internal reflection and always makes it oriented to the search for continuous achievements (Reich, 1980).

8. Every group needs respect based on personal knowledge and mutual trust (Goldstein, \& Sacks, 2000).

9. Every group needs to build goals based on their own resources and perceptions. This means boostering a climate open to personal respect and intimate contact with the facilitator (Horney, 1950).

\section{Method}

Based on the premises stated before about individual-group balance and strategy for individual and group development, we applied the Ed-Way (www.ed-way.eu) findings and results; Ed-Way is a KA2 Erasmus+ Strategic partnership project coordinated by "Centre for the Innovation and Development of Education and Technology" ("CIDET"). This project produced a manual (in press) that facilitates, by means of the usage of new technologies, the use of ICT-based tools and activities, the acquisition of personal, social and formal skills, competences and qualifications. However, these competences are not subject-based (as it could be in courses about history, economy, sciences, law, etc.) but they are based on common skills that are required when dealing with intrinsic motivation, individual leadership, collaboration, creativity and group aims.

In Table 1 we described the 7 phases of the method proposed. In each phase there is a task that we describe shortly afterwards, relating it with ICT-based activities. Each of the phases input is based on the previous phase output. 
Table 1. Phases for personal and group growth

\begin{tabular}{cccc}
\hline Phase & Relational theory & Task & Aim \\
\hline 1 & Personal motivation & Timeline & Emotional intelligence \\
2 & Personal Leadership & Empathy Map & Positive thinking \\
3 & Workgroup & Wheel of needs & Temp phases \\
4 & Objectives targeting & Need list & Building learning challenges \\
5 & Use of language & Impact map & Expressing positively \\
6 & Perception phases & Personal evaluation & Constructive dialogue \\
\hline
\end{tabular}

\section{Piloting}

We applied the method described in the previous section in the online learning platform Edueca (www.edueca.com). We proposed a project-based learning activity to 17 learners and monitored them while they were going through the 7 previous steps during 3 months.

\section{Table 2. ICT based activities}

\begin{tabular}{ll}
\hline Phase & \multicolumn{1}{c}{ ICT-Tool (Edueca) } \\
\hline 1 & Work individually to fill a board about present individual situation, background and \\
& interests. Board allows open replies, and results are shared afterwards to all the group. We \\
& only want the exposition of the members, creating an assertive working environment, \\
& everybody understand other people aims. Voting system allowed to put in common the \\
& most preferred aims.
\end{tabular}

2 Work in pairs (synchronous). The main objective is to know other people talent, potentialities. In this phase, links that are beginning to be created, will later be useful for the constitution of a collaborative group. This is repeated 3 times mixing team members. New roles are listed and classified. Edueca stores these preferences (links between aims, potentialities and interests).

3 3-people team (asynchronous) builds a common vision. We envisage what we can reach based on our own potentialities and aims. This is repeated 2-3 times mixing team members. Results in previous phases are now evaluated by each member of the team and finally by the whole group.

4 4-people team (asynchronous) with the common aim decided in the previous phase, they can place the challenges they find towards success using a virtual board. The potentialities (in 2nd phase) are annexed in this board as resources, and linked to 
individual aims (as stated in 1st phase), creating a graphic with nodes.

Individually (in a board) take decisions (steps) that would guide the group to the achievement of the general aims. The "sentences" used by the members should be always positive. Edueca makes possible to repeat these steps to link decision among members building networks of interests (that are both-direction flows) or networks of needs (one direction flows). These decisions are laters transformed in actions plans, that follow a path from present situation to the final aim.

6 As main learning activity happens, blocking situations appear, alternative aims could be considered. This is an individual activity where learners publish the issues and challenges that appear to the public. The group is the one that decides what to do by trying to find a solution (interactive process) Edueca uses walls, graphs and selection of skills modification of aims forms for the unblock of the scenario.

Conclusion reach by the visualization of aims achieved, but an open discussion (asynchronous in a forum) about how to proceed afterwards.

\section{Results}

The piloting was applied to a 9 learners between 20 and 41 years old enrolled in an online course "Natural resources management" which included the development of a project (report describing the strategy and actions) related to protect and preserve a natural resource. After the training phase where they had to access materials, videos and submit some tasks (reports and questionnaire), they started the developmental phase guided by an online facilitator as stated in Table 2 phases. Learners' experience was observed and conclusions were gathered and summarised in Table 3.

Table 3. Examination conclusions (participant observation)

\begin{tabular}{ll}
\hline Phase & Results \\
\hline 1 & This resulted in an increased awareness of the group of the different background and needs \\
of the participants. It was revealed in the online board not only the interests of the \\
participants but also their personal situation (work, family, life) and hope. More common \\
needs (objectively) were classified and selected among the group. Participants \\
acknowledged that visualising other learner's needs and interests help them to know new \\
applications of topics covered in the course. \\
Learners were capable to explain the strengths and weakness to others, but the fact of doing \\
this in pairs, helped to weight them, discover new talents and reduce the weaknesses \\
importance. It has been difficult to identify which are the good talents or if they could be \\
useful. In this phase it was only aimed to show as much as possible. A virtual list of talents \\
was published, and later organised by categories and areas and new roles arise from this
\end{tabular}


organisation. It was not possible to link them with the previous phase needs as it was planned, so the facilitator considered to wait for next phase.

3 The 3-people team had access to a board where they could select all the aims (from phase 1) and the talents (phase 2), this allows to create linking and strategies. We moved from personal and individual aims to group strategies. This activity resulted as a brainstorming, concluding with a lot of different strategies. A huge effort was put here to try to clarify these aims. Some groups resulted on very wide, general, and abstract objectives, while others proposed direct activities (too operational).

$4 \quad$ With the group strategy selected, in a discussion (using a forum) 4-people team extracted the challenges, risks and issues that make difficult the implementation of the action plan. So far, the main purpose was to detect those difficulties and arrange the actions (timing) linking with the talents (identified in phase 2).

5 Each learner, having the general vision of the project, and with the challenges identified proposes solutions, alternate actions or changes using a positive language. Learners could also suggest changes to previous action plan base in their own interests, motivation and expertise. The project is now being produced (in a form of shared document) which includes a logical structure (path to achieve the general group strategy) based on individual talents, skills and motivations. Edueca worked as a social network.

6 Puting the action plan in practise (at least, only initially) makes possible to see that some of the actions proposed were too complex with low impact. Difficulties on the group management arises, some of them were solved by the mediation of the facilitator. The fact of having clear the individual aims (and most important, the talents) from the beginning and the group strategy helped to drive the building of the project.

7 Project ends with the creation of a common and agreed product, but we did not want to focus on this, but on how the process went, competences learnt, attitudes and values acquired. This summary was done as in a way of questionnaire: How I felt, What I have learnt, Why it was useful for me, that later was made public to all the group and allowed each other to give feedback (as in a way of open forum).

Learners valued the fact of being capable to create a new project as a group that mixed so many talents, opinions and needs, although they agreed that required extra time and effort not only to work collaboratively, but also during the initial phases, where they had to decide what should have been done, and how. We concluded:

Learners could put into practise the topics they learnt in the first stages of the course (that was more theoretical), while at the same time, they had to contextualize and give a purpose, moving to theory to an specific aim. That potentiate the skills and competences that were part of the course. 
The fact of having to provide opinion, defend some aspects of the project and try to understand other learners position help them not only understand better some of the topics of the course, but also to communicate, analyse and propose, discovering new perspectives of the course contents and personal points of view or aspects (problems, potentialities) they were not aware.

Learners acquired soft skills and transversal competences, as communication, leadership, responsibility, plannification, teamwork, etc. This learning was produced informally as it was not planned; it was observed after the evaluation of the course, in fact, some learners had difficulties on this, which we consider positive as those are necessary job-skills not usually targeted.

The way of working (from phase 1 to 7 , from individual to group) increased their awareness of the necessity of work in an interdisciplinary team, and still being possible to fulfill everybody motivation, including the acceptance of having to give in. Depending on the needs of the professor it is still possible to implement part of the method proposed partly as we designed it modular.

The professor acts a facilitator, not teaching, promoting the individual development while guiding the group to a common aim. This requires specific skills and techniques which are not covered in this paper, but are part of the Ed-Way project which includes a training programme for professors.

\section{Acknowledgments}

This paper has been developed from the experience in the KA2 Erasmus+ Strategic Partnership project "education on the way: Introducing technology-enhanced informal learning” with reference 2015-1-ES01-KA204-016354 www.ed-way.eu

\section{References}

Cabero-Almenara, J. (2006). Bases pedagógicas del e-learning. RUSC. Universities and Knowledge Society Journal, 3(1), 1.

Clark, R. C., \& Mayer, R. E. (2016). E-Learning and the Science of Instruction: Proven Guidelines for Consumers and Designers of Multimedia Learning. John Wiley \& Sons.

Couros, A. (2010). Developing personal learning networks for open and social learning. Emerging technologies in distance education, 109-128.

Eurostat (2017). Digital economy and society statistics - households and individuals Statistics Explained. (n.d.). Retrieved January 4, 2017

Ferreira, B., Silva, W., Oliveira, E., \& Conte, T. (2015). Designing Personas with Empathy Map. 
Fitó-Bertran, À., Hernández-Lara, A. B., \& Serradell-López, E. S. (2015). The effect of competences on learning results an educational experience with a business simulator. Computers in Human Behavior, 51, Part B, 910-914.

Friedman, M. S. (2002). Martin Buber: The Life of Dialogue. Psychology Press.

Gallego, T \& Lopez-Mesa B (2007), Implementation of project-based learning in building engineering in Spain, 16th International Conference on Engineering Design, Paris.

Goodman, P. (1966). Compulsory Mis-Education and the Community of Scholars. New York: Random House Trade Paperbacks.

Goodman, P., Hefferline, R. F., \& Perls, F. S. (1951). Gestalt Therapy: Excitement and Growth in the Human Personality. Highland, NY: Gestalt Journal Press.

Goldstein, K., \& Sacks, O. (2000). The Organism. New York: MIT Press.

Horney, K. (1950). Neurosis and Human Growth: The Struggle Towards Self-Realization: The Struggle Toward Self-realization by Karen Horney. W. W. Norton \& Company.

Lewin, K. (1947). Frontiers in group dynamics. I. Concept, method and reality in social science; social equilibria . Human Relations.

Macintyre, J. (2012). Lifeline work: community-based adult learning and learners' personal progression. Studies in the Education of Adults, 44(2), 186-203.

Max-Neef, M. A. (1992). From the outside looking in: experiences in "barefoot economics." London: Atlantic Highlands, New Jersey, USA : Zed Books.

Noble, T., \& McGrath, H. (2008). The positive educational practices framework: A tool for facilitating the work of educational psychologists in promoting pupil wellbeing. Educational and Child Psychology, 25(2), 119-134.

Polster, E., \& Polster, M. (1974). Gestalt Therapy Integrated: Contours of Theory \& Practice: Contours of Theory and Practice. New York: Vintage Books.

Reich, W. (1980). Character Analysis. (V. Carfagno, Trans.) (3 edition). New York: Farrar, Straus and Giroux.

Satir, V. (1988). New Peoplemaking (Edición: 00002). Mountain View, Calif: Science \& Behavior Books Inc.

Serradell-López, E. (2014) El uso de los juegos y simuladores de negocio en un entorno docente. Oikonomics, revista de economía, empresa y sociedad. Universitat Oberta de Cataluyna

Veletsianos, G. (Ed.). (2010). Emerging technologies in distance education. Edmonton: AU Press.

Watson, S. L. (2007). An Argument for Clarity: What are Learning Management Systems, What are They Not, and What Should They Become? William R. Watson Indiana University-Purdue University Indianapolis.

Weller, M. (2007). Virtual Learning Environments: Using, Choosing and Developing Your VLE. Routledge. 